\title{
LA CRISIS FINANCIERA INTERNACIONAL. ¿LLEGARÁ?
}

\section{Dr. PASCUAL CHÁVEZ ACKERMANN}

Desde los primeros días de junio, han ocurrido una serie de extraordinarios acontecimientos en los mercados financieros mundiales que, si se analizan cada uno de ellos por separado, no parecen tener mayor significado. Pero, si estos hechos se consideran como parte de un solo proceso global, entonces no podemos llegar sino a la conclusión de que ya ocurrió a principios de junio otro desastre financiero, parecido a la quiebra en setiembre de 1998 del fondo financiero de apuestas especulativas LTCM (Long Term Capital Management), y que se pusieron en marcha una serie de esfuerzos de alto nivel para ocultar la realidad o para administrar la crisis, todo ello para prevenir que cunda el pánico en los mercados financieros internacionales.

En un discurso pronunciado ante la Casa Mansión en Londres el 10 de junio, el gobernador del Banco de Inglaterra, Eddie George, recalcó cuán cerca había llegado el mundo a la desintegración financiera en el otoño de 1998. "La última vez que estuvimos aquí para esta espléndida ocasión, yo sugerí que estábamos viviendo en un ambiente económico y financiero internacional peligroso. Estas fueron palabras fuertes para un banquero central -pero quizás no lo suficientemente fuerte-. Ese ambiente rápidamente empeoró en el transcurso del otoño, y para las fechas de la reunión anual del FMI (Fondo Monetario Internacional), en octubre, ya todo mundo hablaba de una desintegración financiera global y una próxima recesión mundial, lo que no era simplemente hipérbole periodística".
La notable declaración de George se debe evaluar junto a las confesiones parecidas hechas por el presidente del BLI (Banco de Liquidaciones Internacionales), Urban Baeckstroem, el director administrativo del FMI, Michel Camdessus, y el exsubsecretario del tesorero de los Estados Unidos, Roger Altman. Simultáneamente, el Banco de Inglaterra advirtió en su "Reseña sobre la estabilidad financiera" de junio de 1999 que algunos bancos parecen haber olvidado "las lecciones de los acontecimientos del año pasado", y que de nuevo están expandiendo sus préstamos a "instituciones altamente apalancadas".

Esa misma semana, se difundieron los rumores en los círculos financieros internacionales de que la Reserva Federal estadounidense había sostenido discusiones secretas con el Tiger Management Fund de Julian Robertson, uno de los más grandes fondos de especulación en el mundo, con unos 13.000 millones de dólares en activos, para discutir la crisis por la que estaría pasando ese fondo. Como ahora lo reconoce todo mundo, había puesto a todo el sistema financiero internacional al borde de la desintegración.

El pasado 11 de junio hubo una venta casi de pánico en el mercado de bonos a 30 años del Tesoro de los Estados Unidos, lo que provocó un aumento en los rendimientos de los mismos a 6,18 por ciento. Pero cuidadosamente, para fines de esa semana, se impuso en los medios de comunicación un silencio sepulcral sobre el caso de Tiger Fund, y empezaron a bajar los rendimientos. Fuentes bien informadas 
piensan que intervino la Reserva Federal para silenciar los rumores: según los expertos, si la venta acelerada de bonos hubiera elevado los rendimientos por encima de 6,2 por ciento, hubiera habido una desintegración en cascada en los bonos globales y las bolsas de valores.

\section{GREENSPAN:}

\section{"La Burbuja se puede Administrar".}

El pasado 17 de junio, el presidente de la Reserva Federal de los Estados Unidos, Alan Greenspan, trató de calmar las aguas al comparecer ante la Comisión Económica Conjunta del Congreso, donde elogió la dizque prosperidad de los Estados Unidos. Sin embargo, tuvo que admitir la existencia del problema de una burbuja en los mercados financieros estadounidenses.

"¿Qué hacer? Déjenmelo a mí y a la Reserva Federal", dijo. Nosotros podemos administrarla. "Aunque el estallido de una burbuja no es benificioso que digamos, las consecuencias no tienen que ser catastróficas".

Este es el mismo Alan Greenspan que, en diciembre de 1996, advirtió de la existencia de una exuberancia irracional en la bolsa de valores porque el índice Down Jones iba en los 6.400 puntos. Pero hoy en día, tres años más tarde, el Down Jones está por encima de los 10.000 puntos.... iy Greenspan insiste que se puede administrar la burbuja!.

El connotado economista estadounidense Lyndon La Rouche comentó estos esfuerzos de Greenspan de apuntalar la insolvente arquitectura financiera global: "Alan Greenspan está dispuesto a arrojar todo y a todos en el fuego de los refinanciamientos hiperinflacionarios con tal de sostener -aunque sea por un mes más- una estructura irracional. No quieren aceptar la realidad de que el actual sistema financiero global está irremediablemente en bancarrota, y que cada nueva bocanada de aire que obtiene el sistema, asegura que el desenlace explosivo sea peor. Y todo esto porque no quieren aceptar de una buena vez, mi Nuevo Breton Woods".

"La burbuja financiera más grande, el último dominó de la cadena, el pagaré final cuya devaluación va a mandar directo por el caño a todo el sistema financiero mundial dominado por la City de Londres, es Wall Street", añadió La Rouche.

Es de esperarse que el próximo año 2000 sea el inicio de una conmoción financiera aún mayor ya que en esa fecha concluye el segundo trimestre a la par que finalizó el año físcal de los estados de Estados Unidos; así como también, termina el año fiscal de otras entidades. Para esa fecha también se espera un aumento de un cuarto de punto en la tasa de interés de los Estados Unidos.

En Japón y en Europa, ya se vislumbran grandes problemas. El pasado 18 de junio el Banco de Japón permitió la intervención abierta del BCE (Banco Central Europeo) para frenar una caída mayor del euro respecto al yen, que a la vez estabilizó un alicaído euro respecto al dólar. A primera hora del $18 \mathrm{de}$ junio, el euro había bajado su cotización a 1,03 por dólar, lo que desató rumores sobre posibles ventas mayores de euros en los mercados globales de parte de los japoneses y otros inversionistas. Esta fue la primera vez que tuvo que intervenir directamente el flamante $\mathrm{BCE}$ en los mercados monetarios. La Reserva Federal de los Estados Unidos, el Bundesbank de Alemania y el Banco de Francia también intervinieron para comprar euros, a instancias del Banco de Japón. 
Días más tarde, el 22 de junio, una funcionaria del Banco Central de Japón dijo que la política oficial era mantener virtualmente en cero la tasa de interés japonesa dizque para atraer capitales.

\section{LOS MERCADOS DÉBILES}

Tampoco hay calma en Iberoamérica. El pasado 16 de junio el gobierno mexicano anunció un arreglo sin precedentes con el FMI, Banco Mundial y el Tesoro de los Estados Unidos, mediante el cual México recibiría líneas de crédito combinadas por 23.700 millones de dólares como blindaje financiero ante cualquier eventualidad. Pero habría que preguntarse si esa eventualidad catastrófica no habrá ocurrido ya aún sin que nadie lo admita. Por ejemplo, entre junio de 1999 y diciembre del 2000 , vencen aproximadamente 25.000 millones de dólares en deuda extranjera del sector privado no financiero mexicano; esto sin contar los 17.000 millones en préstamos a corto plazo del sector bancario que vencen en el mismo lapso.

En Brasil, las reservas internacionales tuvieron una caída de 1.500 millones de dólares en un solo día, el 18 de junio. Y el nerviosismo ha aumentado con las admisiones del gobierno de que tanto el déficit fiscal como el comercial, van a ser más de lo que se esperaba.

En otros continentes es menor la sumisión a las políticas de la usura internacional y hay naciones que están tomando rutas alternas para salvar sus economías nacionales, que incluye el control de capitales, el congelamiento de la deuda, entre otras cosas. En Nigeria, por ejemplo, donde el 90 por ciento de las divisas extranjeras son producto de los ingresos petroleros -y que actualmente, son insuficientes para cubrir el servicio de la deuda externa-el gobierno decretó el 21 de junio controles a las divisas extranjeras, después de que sus reservas cayeron de 7.100 a 4.000 millones de dólares, en menos de seis meses. En Indonesia, se dio una discusión similar en el partido de Megawati Sukarnoputri, ganador de las recientes elecciones presidenciales en ese país. 